Article

\title{
Performance Evaluation of a Permanent Magnet- Assisted Synchronous Reluctance Machine with Hybrid Magnets of Ferrite Magnets and Rare-earth PMs
}

\author{
Xiping Liu, Ya Li * and Zhangqi Liu \\ School of Electrical Engineering and Automation, Jiangxi University of Science and Technology, Ganzhou, \\ 341000, China; liuxp211@163.com; ly122810@163.com; sxtdlzhq@163.com; \\ * Correspondence: ly122810@163.com; Tel.: +96-155-7012-8445
}

\begin{abstract}
In this paper, a novel permanent magnet-assisted synchronous reluctance machine (PMASynRM) with rare-earth PMs and ferrite magnets is proposed. The performance of PMASynRM is discussed with respected to the different magnet ratio of rare-earth PMs and ferrite magnets. Some characteristics including the flux density, output torque, cogging torque, output power, power factor, torque ripple, loss, efficiency, and demagnetization are calculated by 2-D finite element analysis (FEA). The analysis results show that the excellent performance can be obtained by using hybrid magnet of rare-earth PMs and ferrite magnets with the suitable magnet ratio, and provide some desirable cost-performance trade-off.
\end{abstract}

Keywords: permanent magnet-assisted synchronous reluctance machine; power factor; torque ripple; efficiency; demagnetization; finite element analysis

\section{Introduction}

Currently, permanent magnet electrical machines with rare-earth permanent magnets (PMs) exhibit excellent performances, such as power density, torque density, efficiency, power factor and a wide speed-regulation region [1-3]. However, there are some limits of the high cost and supply chain uncertainty for rare-earth PMs because of neodymium and dysprosium. Therefore, less or no rareearth PMs in electrical machines can be considered to decrease the total cost of electrical machines. Although some electrical machines without rare-earth PMs can achieve some excellent performance including high power density, high torque density and high efficiency, such as switch reluctance machines (SRMs) [4-8] and synchronous reluctance machines (SynRMs) [9-12]. Nonetheless, there are some problems, such as the vibration and acoustic noise in SRMs [13-15], and low power factor in SynRMs [16-19]. Moreover, rare-earth PMs can be partially replaced by low-cost ferrite magnets [2032]. Although the performance of electrical machines with ferrite magnets can be improved, there are still some shortcomings, such as low power factor and low torque density due to low remanence of ferrite magnets.

In order to achieve high performance and reduce total cost of electrical machines, a novel permanent magnet-assisted synchronous reluctance machine (PMASynRM) with hybrid magnet of rare-earth PMs and ferrite magnets is proposed, of which the magnet ratio is an important factor of PMASynRM. In addition, the irreversible demagnetization of ferrite magnets should be considered when it operates in cold weather [33-35].

Therefore, the purpose of this paper is to investigate the performance of PMASynRM by using hybrid magnets with different magnet ratio. Some electromagnetic characteristics including flux density, output torque, cogging torque, output power, field-weakening capacity, power factor, torque ripple, loss and efficiency were calculated by 2-D finite element analysis (FEA). Meanwhile, the 
irreversible demagnetization behavior was examined in the worst condition of critical temperature ($\left.40^{\circ} \mathrm{C}\right)$.

\section{Topology of PMASynRM and Parameter}

\subsection{Machine Topology}

Fig. 1 shows the stator of PMASynRM, of which the slot number is 48 and a distributed armature winding is applied.

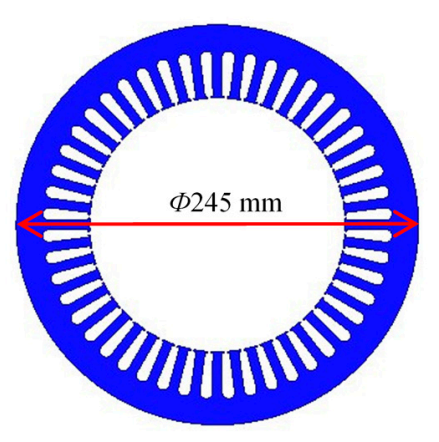

Fig 1. Structure of stator.

Fig. 2(a) gives the 2D structure model of rotor, which mainly includes iron bridges, flux barriers, center ribs and rectangular PMs. The center ribs are designed trial and error to decrease flux leakage and achieve sufficient mechanical strength. The rectangular PMs are embed into rotor iron to produce radial magnetic field in PMASynRM. Some parameters including the shape and size of flux barriers, the width of iron bridges and center ribs, are optimized in literature [36]. Meanwhile, some characteristics with response to torque ripple, loss, efficiency, mechanical strength and irreversible demagnetization are discussed. Although the multi-layer of ferrite magnets was designed in the rotor of PMASynRM to increase the reluctance torque, the flux density is low because of the low remanence of ferrite magnets, and the power factor and torque density are not ideal. Therefore, the rotor topology with ferrite magnets and rare-earth PMs is proposed for improving the performance and reducing the cost of machine, as shown in Fig. 2(b). Meanwhile, as shown in Fig. 1(a), (b) and (c), the shape and thickness of flux barriers are the same, and the equal sizes of iron bridges and center ribs are adopted, but the magnet ratios of three models are different.

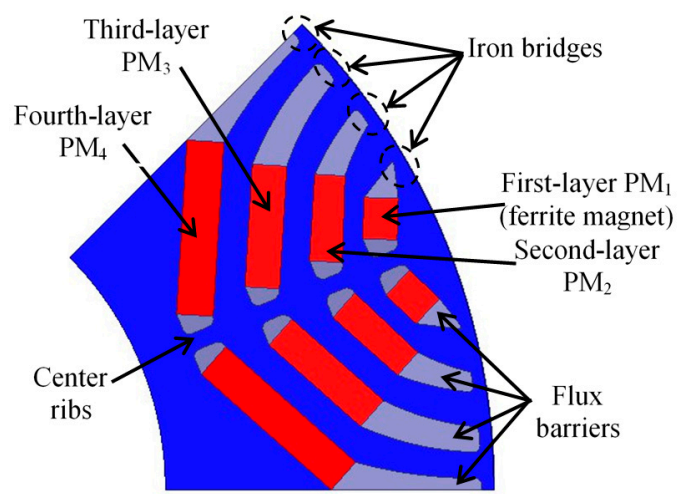

(a) 


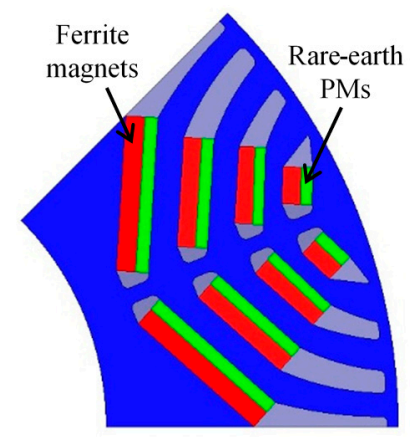

(b)

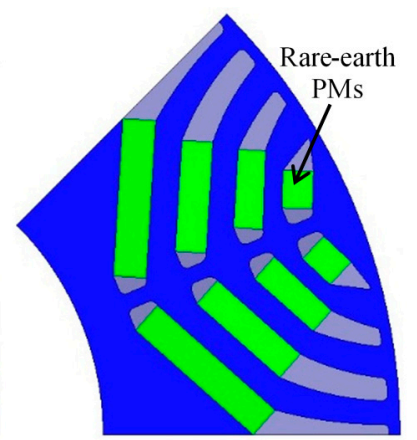

(c)

Fig 2. Rotor structure of PMASynRM with different PMs. (a) Ferrite magnets. (b) Ferrite magnets and rare-earth PMs. (c) Rare-earth PMs.

Some parameters are given in Table. 1, which consists of pole number, outer diameter of stator, stack length, voltage in DC side, slot fill factor and winding resistance at $20{ }^{\circ} \mathrm{C}$. Meanwhile, the coercive force of ferrite magnet and rare-earth PMs are also given in Table. 1 respectively.

Table .1 Some parameters of PMASynRM

\begin{tabular}{cc}
\hline Item (Unit) & Value \\
\hline Number of poles & 8 \\
Outer diameter of stator $(\mathrm{mm})$ & 245 \\
Stack length $(\mathrm{mm})$ & 70 \\
Max. DC side voltage $(\mathrm{V})$ & 650 \\
Ferrite magnet & $\mathrm{Y} 30 \mathrm{BH}$ \\
Coercive force of ferrite magnet $(\mathrm{kA} / \mathrm{m})$ & 232 \\
Rare-earth PMs & $\mathrm{N} 36 \_\mathrm{Z} 20$ \\
Coercive force of rare-earth PMs $(\mathrm{kA} / \mathrm{m})$ & 920 \\
Slot fill factor $(\%)$ & 52.3 \\
Winding resistance at $20{ }^{\circ} \mathrm{C}(\Omega)$ & 0.0646 \\
\hline
\end{tabular}

\subsection{Magnet Ratio}

In order to simplify the analysis model, the magnet ratio of $\mathrm{k}$ is defined as following

$$
k=\frac{V_{r e}}{V_{r e}+V_{f m}}
$$

where Vre is total volume of rare-earth PMs, Vfm is the total volume of ferrite magnets. The rareearth PMs and ferrite magnets are excited serially, and the width of every PMs is same, so the magnet ratio can also be defined by equation (2)

$$
k=\frac{h_{r e}}{h_{r e}+h_{f m}}
$$

where hre and hfm are the thickness of rare-earth PMs and ferrite magnets, respectively, as shown in Fig. 3. In order to reduce the parameters of PMs, $\mathrm{k}$ is defined as same for each PM. It is worth noticing that $\mathrm{k}$ is 0,1 represent the proposed PMASynRM with only ferrite magnets and only rare-earth PMs, respectively. 


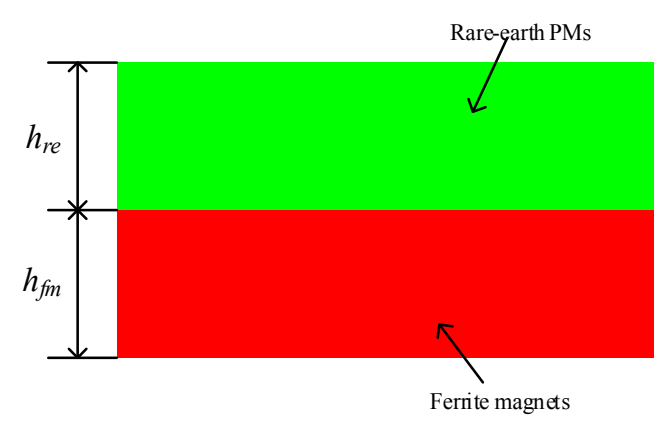

Fig 3. Thickness of PMs.

\section{Performance Evaluation}

For the purpose of decreasing computation time and maintaining a higher precision, one-eighth model and odd symmetry boundary condition is adopted in PMASynRM. In this section, some performances are computed and analyzed comparatively, such as some electromagnetic characteristics including output power, output torque, cogging torque, torque ripple, power factor, rotor loss, stator loss and efficiency are calculated in constant region and field-weakening condition.

\subsection{Flux density}

The flux density in the rotor and stator at no load is shown in Fig. 4. It can be found that flux density increased with the increasing of magnet ratio. In addition, the flux density in center ribs and iron bridges are saturated because of flux leakage. Although rare-earth PMs can provide more magnetic energy to achieve the higher torque density, it also causes magnetic field saturated and the increasing of iron loss. Furthermore, the magnet ratio should be designed to improve the utilization rate of rare-earth PMs in consideration of its higher price.

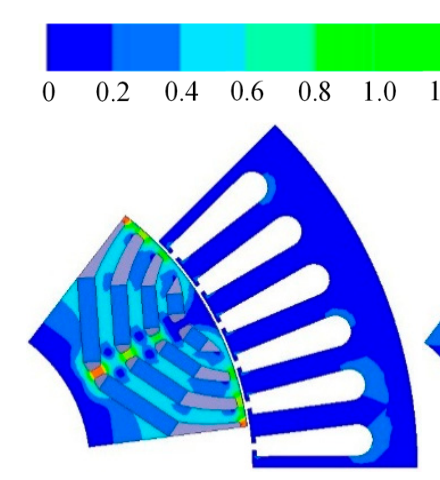

(a)

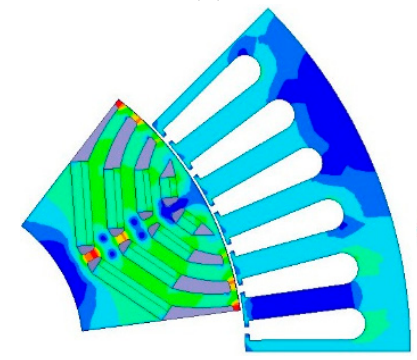

(c)

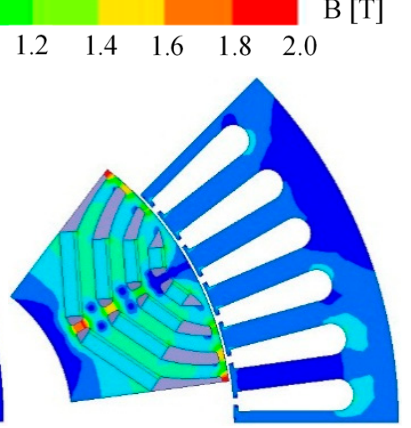

(b)

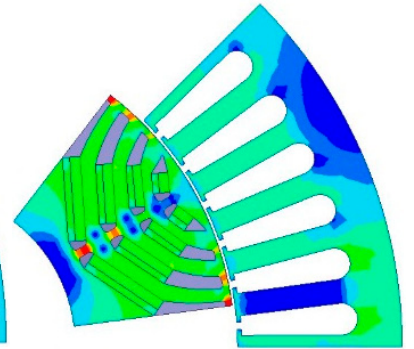

(d) 


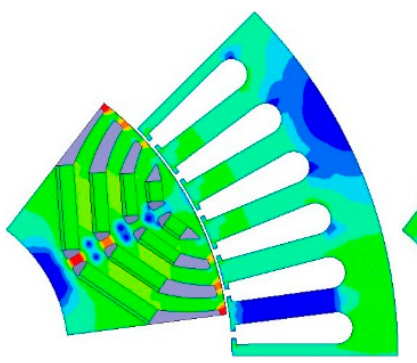

(e)

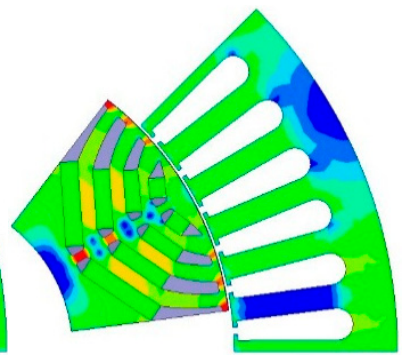

(f)

Fig 4. Flux density of rotor and stator at no load. (a) $k=0$. (b) $k=0.2$. (c) $k=0.4$. (d) $k=0.6$. (e) $k=0.8$. (f) $k=1.0$.

\subsection{Torque characteristics}

As the dc-side voltage is assumed to be $650 \mathrm{~V}$, the RMS value of line-to-line voltage was set to $450 \mathrm{~V}$, and the maximum phase current is $200 \mathrm{~A}$. The output torque versus current phase angle is given in Fig. 5, which shows that there is a great effect on output torque due to the magnet ratio. $\beta$ (current phase angle) is the leading angle of the current vector from q-axis. The output torque increased with magnet ratio $\mathrm{k}$ because more magnetic energy in air gap has been provided with the increasing of magnet ratio. Furthermore, $\beta$ is completely different at the maximum output torque, and the maximum output torque reaches 204.5 N.m when $k$ is 1 . In addition, it also indicated that the higher torque density can be achieved in PMASynRM by using rare-earth PMs and ferrite magnets with a suitable magnet ratio.

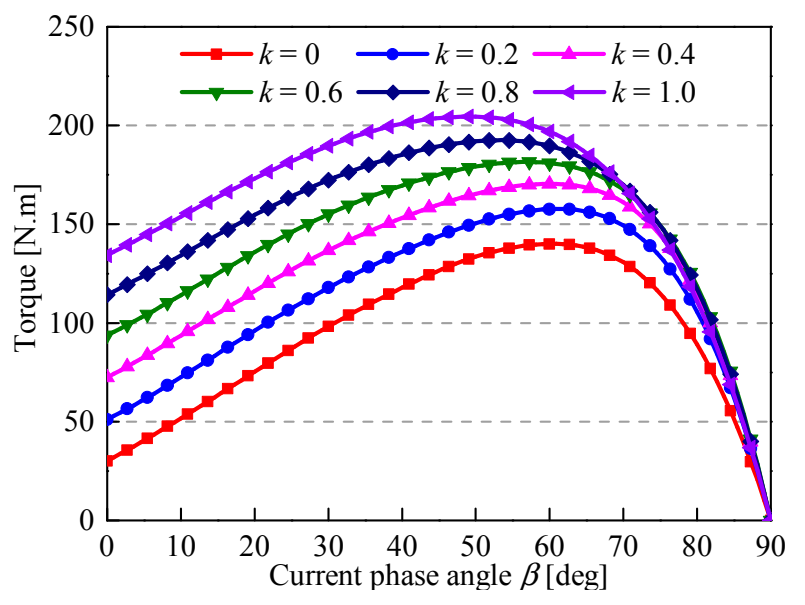

Fig 5. Output torque versus rotor position.

The cogging torque versus rotor position is shown in Fig. 6 . The periods of cogging torque in one electrical cycle can be calculated by the following equation

$$
N=\frac{2 Q}{G C D(Q, 2 P)}
$$

where $\mathrm{N}, \mathrm{Q}, \mathrm{P}$ and GCD are the period number of cogging torque in one electrical cycle, slot number of stator, rotor pole pair and greatest common divisor, respectively.

As shown in Fig. 6, it has 12 periods of cogging torque in one electrical cycle decided by 8 poles and 48 slots of PMASynRM. The amplitude of cogging torque is the largest by adopting rare-earth PMs, and smallest with ferrite magnets. It is determined by the different coercive force and remanence of rare-earth PMs and ferrite magnets, which leads to the different magnet strength and permeance variation of the hybrid magnets in the magnetic circuit. However, the curves of cogging torque are similar, which due to the same rotor and stator structure of PMASynRM. 


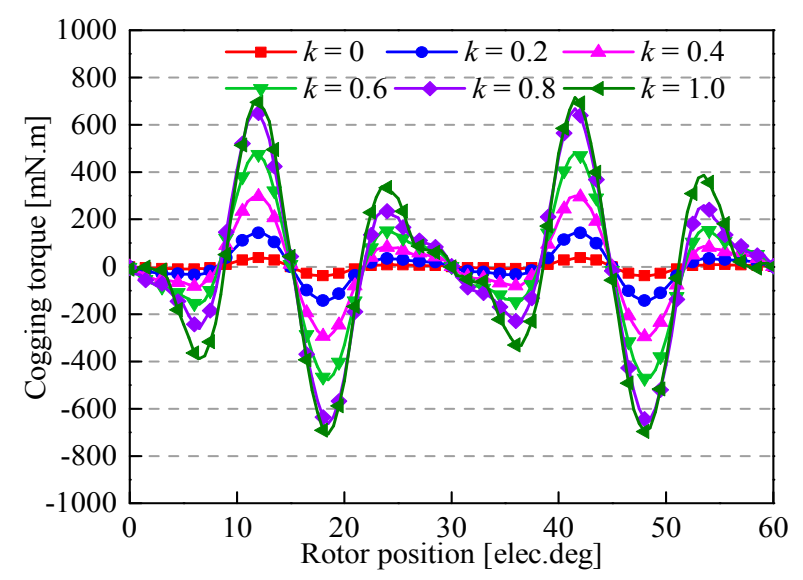

Fig 6. Cogging torque.

\subsection{Output power and capacity of field-weakening}

The output power with different magnet ratio is given in Fig. 7 . The maximum output power is about $98.7 \mathrm{~kW}$ when $k$ is 1 , which is 1.65 times of that the $k$ is 0 . It shows that output power can be increased with augment of magnet ratio, which demonstrated that high power density can be obtained in PMASynRM by using rare-earth PMs and ferrite magnets. Although the output power can be increased with $\mathrm{k}$, the iron loss, power factor and efficiency should be taken into consideration. The capacity of field-weakening for PMASynRM with different magnet ratio is shown in Fig. 8. A wider speed range can be obtained by using rare-earth PMs.

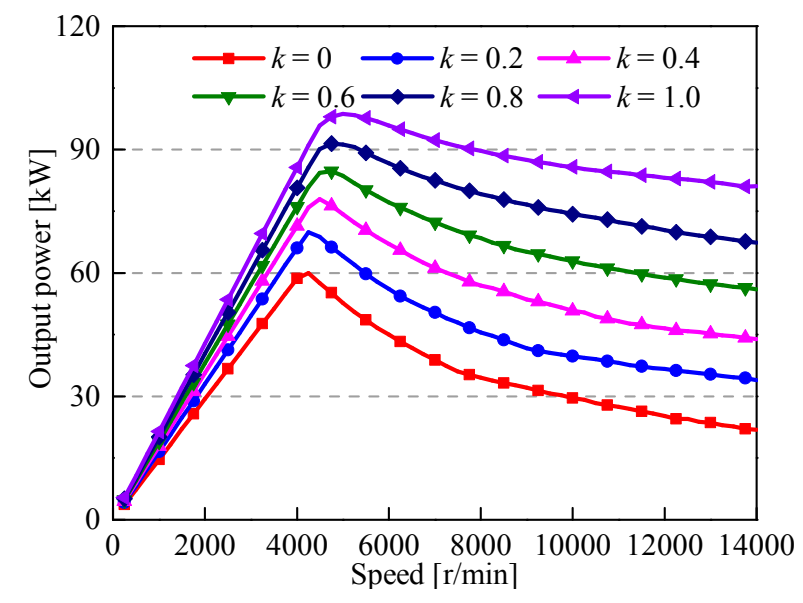

Fig. 7 Output power versus speed.

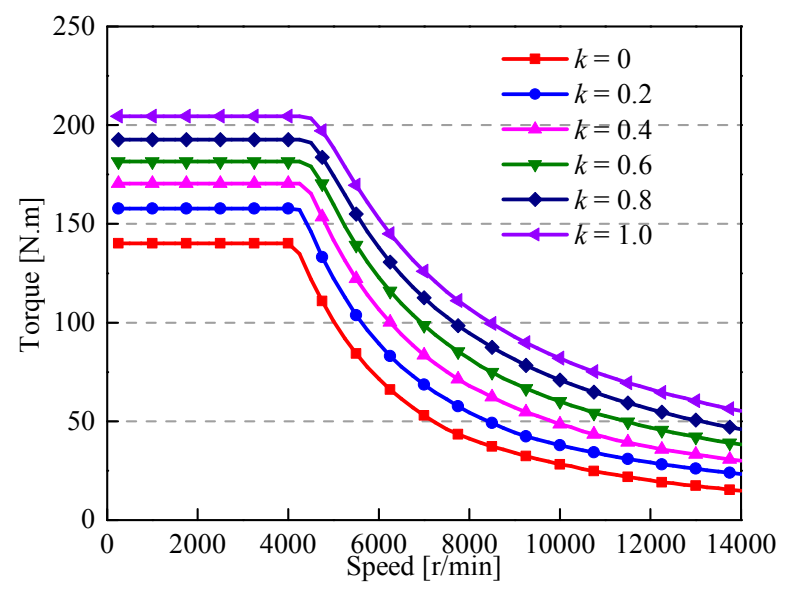


Fig 8. Capacity of field-weakening.

\subsection{Power factor}

In Fig. 9, the power factor-speed characteristics are compared for PMASynRM. The power factor increased with magnet ratio, and it is the largest when $k$ is 1 . Because more rare-earth PMs are adopted in PMASynRM and more magnetic energy is produced in air gap with the increase of magnet ratio. There is an obvious difference for the power factors when $k$ is 0 and 1 , which indicated that the performances of PMs have a great effect on power factor, such as remanence, coercive force, and volume of PMs. Compared with the condition of $k$ is 0 , the power factor can be improved greatly when $\mathrm{k}$ is 0.2 in the high speed region.

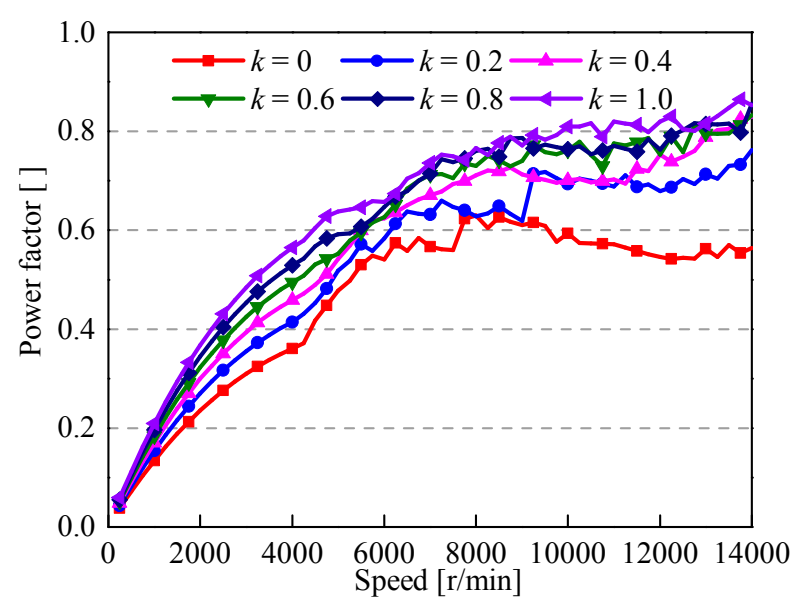

Fig 9. Power factor versus of speed.

Fig. 10 gives the map of power factor. It can be found that high power factor can be obtained by adding some rare-earth PMs in rotor. Moreover, the area of power factor that higher than 0.600 is increased with magnet ratio, which due to much rare-earth PMs with high coercive force and larger remanence are applied in rotor. Therefore, it indicates that the power factor in all the operate area can be improved with an appropriate magnet ratio.

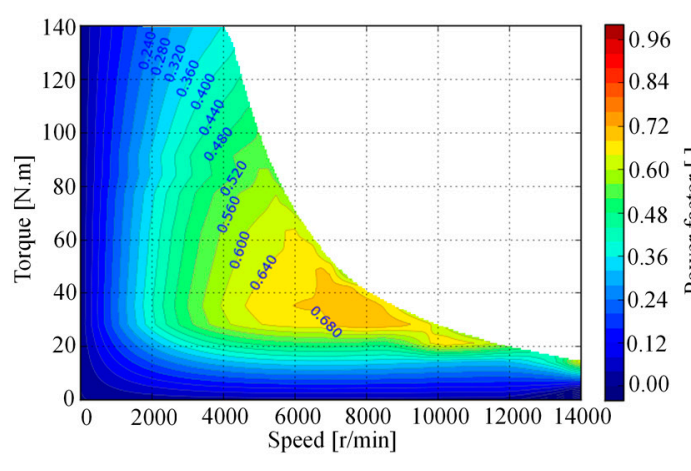

(a)

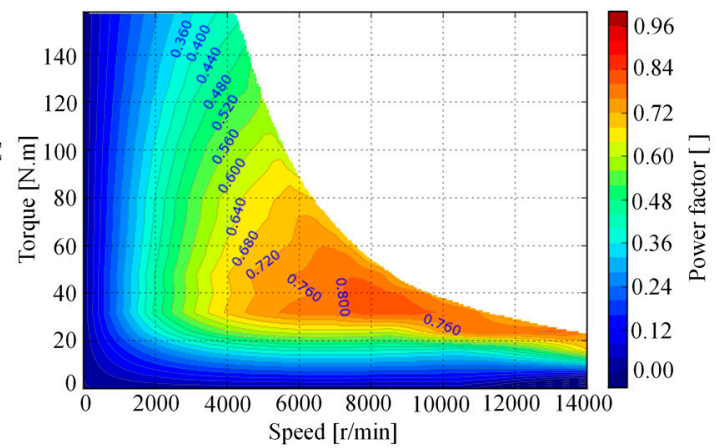

(b) 


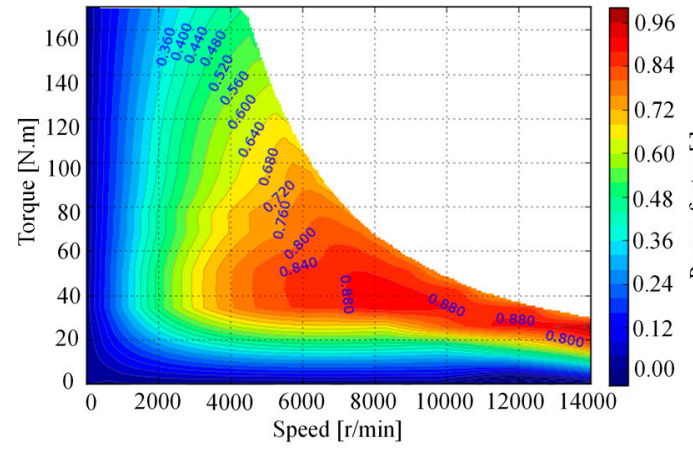

(c)

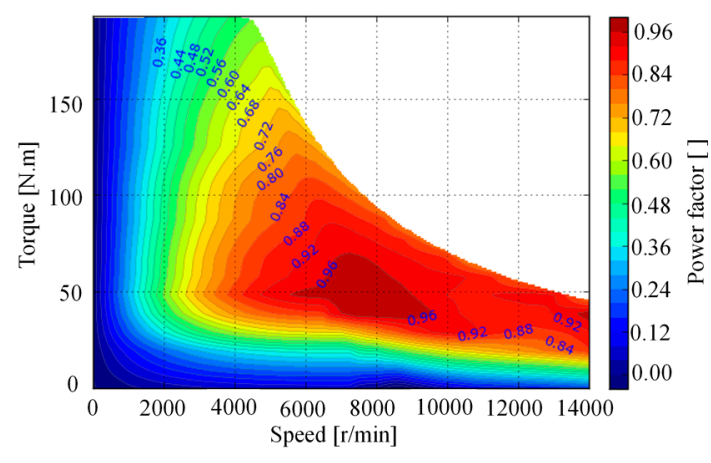

(e)

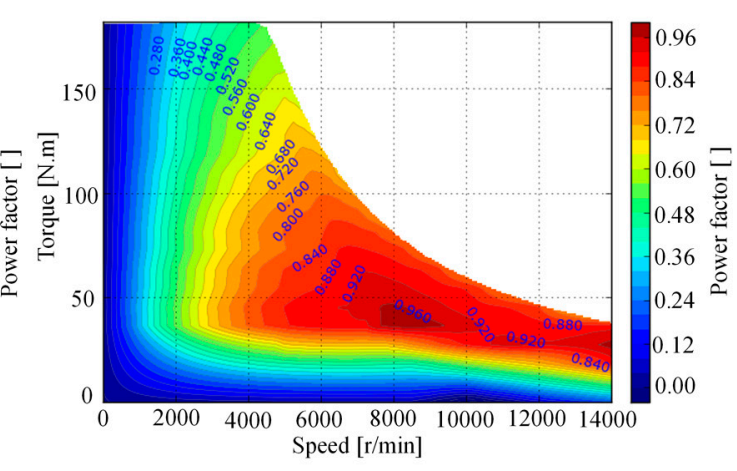

(d)

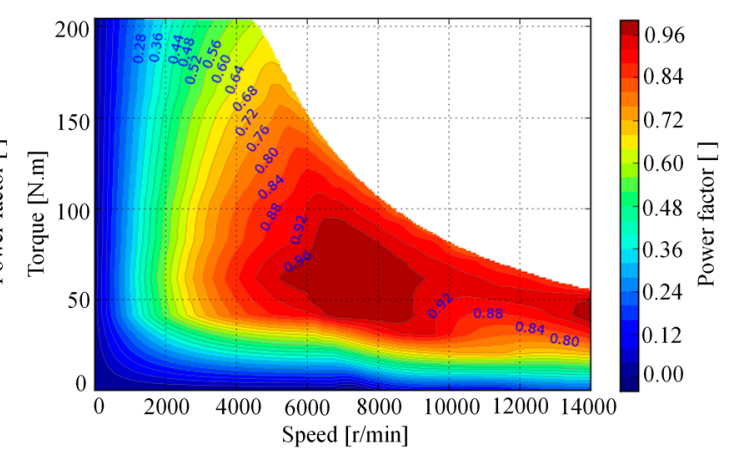

$(\mathbf{f})$

Fig 10. The map of power factor. (a) $k=0$. (b) $k=0.2$. (c) $k=0.4$. (d) $k=0.6$. (e) $k=0.8$. (f) $k=1$.

\subsection{Torque ripple}

The average electromagnetic torque and torque ripple are computed by 2D FEA, and the torque ripple can be defined as

$$
T_{\text {ripple }}=\frac{T_{\max }-T_{\min }}{T_{\text {avg }}}
$$

where $T_{\text {ripple }}$ is the rate of torque ripple, $T_{\max }, T_{\min }$ and $T_{\text {avg }}$ are the maximum torque, the minimum torque and the average torque, respectively.

Although the torque ripple characteristics are investigated in the literature [22], [24], [37-39], there is a limit of computing the torque ripple at a fixed operational condition, such as rated load or the maximum load. In order to obtain a comprehensive comparison for PMASynRM with different magnet ratio, the torque ripple maps in all operational region are given in Fig. 11. It shows that the maximum torque ripple is $13.8 \%, 9.3 \%, 10.5 \%, 9.0,13.8$ and $22.3 \%$ when $k$ is $0,0.2,0.4,0.6,0.8$ and 1 , respectively. It should be noted that PMASynRM with hybrid magnets have a low torque ripple distribution in all operational region when magnet ratio is $0.2,0.4,0.6$ and 0.8 , which indicated that the assumption of hybrid magnet is reasonably. However, the torque ripple increases when the magnet ratio is 1, as shown in Fig. 11(f), which due to the increased of cogging torque and harmonic in air gap flux density. Meanwhile, it also illustrated that the machine structure should be further optimized for improving torque ripple when ferrite magnets are partially replaced with rare-earth PMs in PMASynRM. 


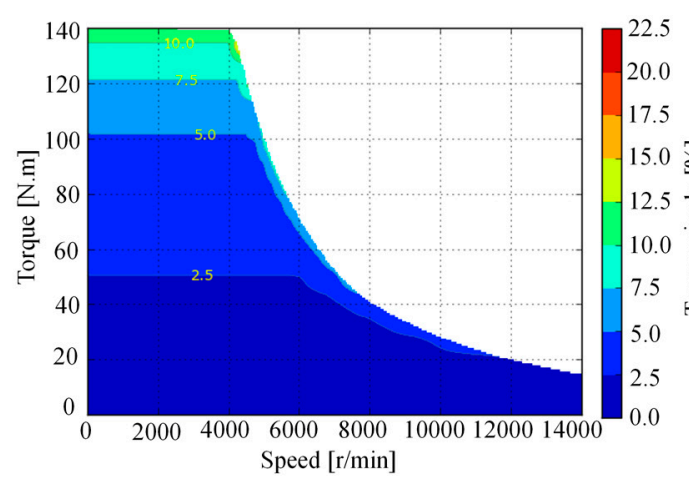

(a)

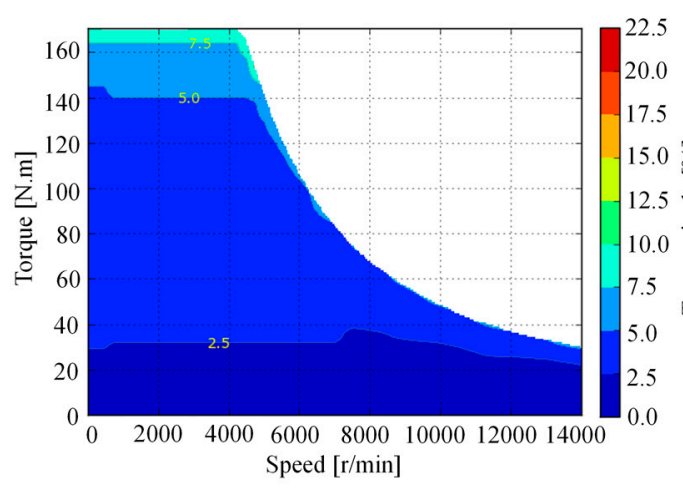

(c)

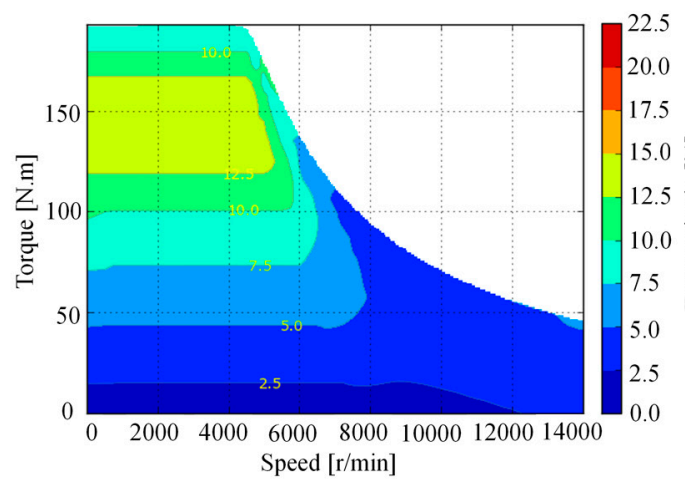

(e)

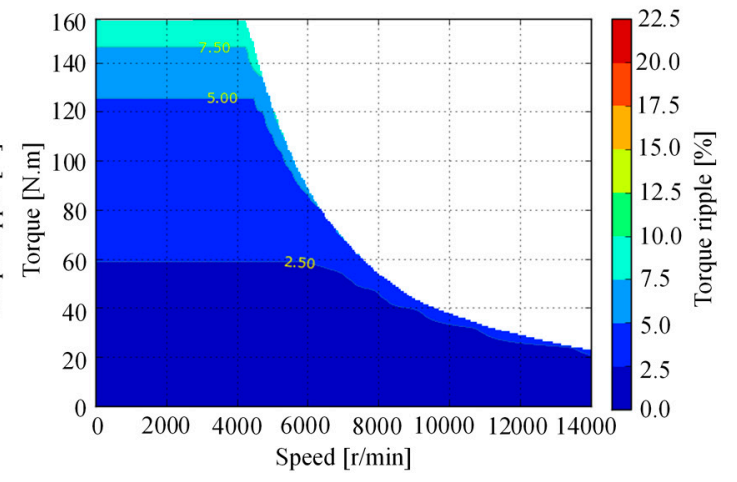

(b)

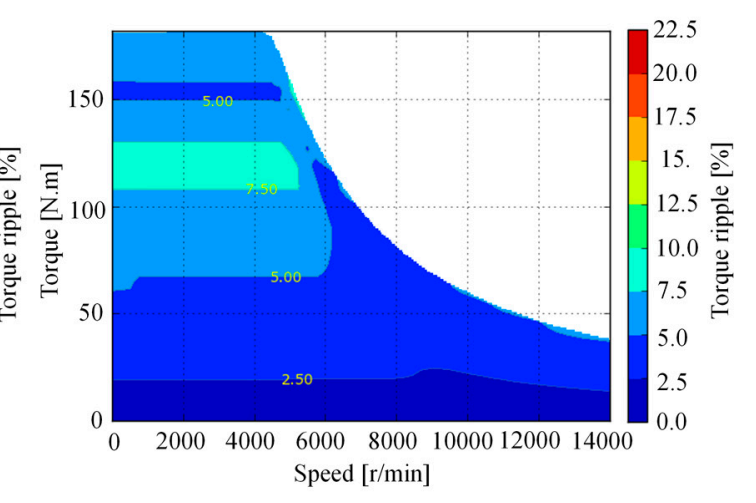

(d)

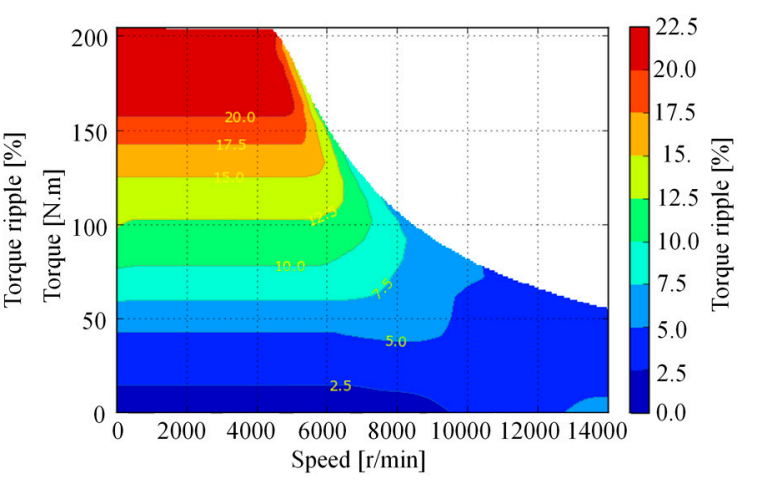

(f)

Fig 11. Torque ripple maps (a) $k=0$. (b) $k=0.2$. (c) $k=0.4$. (d) $k=0.6$. (e) $k=0.8$. (f) $k=1$.

\subsection{Loss and efficiency}

The loss and efficiency are the significant parameters in motors. The iron loss, copper loss and efficiency can be calculated by the following equations

$$
\begin{gathered}
W_{i}=W_{h}+W_{e} \\
W_{c}=3 R_{a} I_{\mathrm{e}}^{2} \\
\eta=\frac{w T}{w T+W_{c}+W_{i}+W_{m}} \times 100
\end{gathered}
$$

where $W_{i}$ is the iron loss [W], $W_{h}$ is the hysteresis loss [W], $W_{e}$ is eddy loss [W], $W_{c}$ is copper loss [W], $R_{a}$ is winding resistance $[\Omega], I_{e}$ is phase current [A], $\eta$ is the efficiency [\%], $T$ is torque $[N . m], w$ is mechanical angular velocity $[\mathrm{rad} / \mathrm{s}], W_{m}$ is mechanical frication loss [W].

Despite of the different magnet ratio when estimating of loss and efficiency, copper loss does not changed with magnet ratio since the same control strategy (MTPA) is adopted. Therefore, iron 
loss is the most important factor for evaluating the total loss and efficiency. The iron loss in PMASynRM with different magnet ratio is given in Fig. 12, which shows that the stator iron loss accounts for a large proportion of the total iron loss. Rotor iron loss increased with speed, as shown in Fig. 12(a). Furthermore, rotor iron loss increased with magnet ratio when the machine speed above $12000 \mathrm{r} / \mathrm{min}$, which due to larger magnet ratio resulting saturation in rotor. Stator iron loss is given in Fig. 12(b), and it can be found that stator iron loss increased with speed. In addition, stator iron loss increased with magnet ratio when operating at speed above $6000 \mathrm{r} / \mathrm{min}$. However, stator iron loss is almost unchanged with magnet ratio when operating at speed under $5000 \mathrm{r} / \mathrm{min}$.

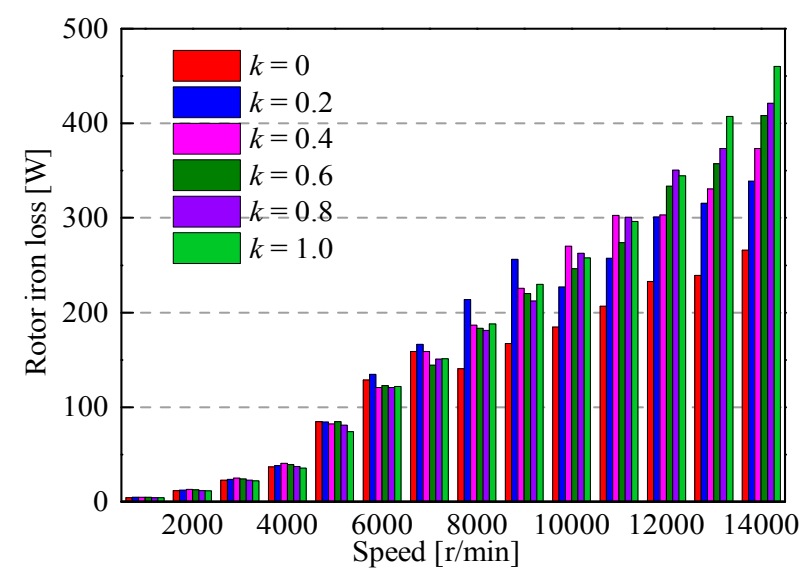

(a)

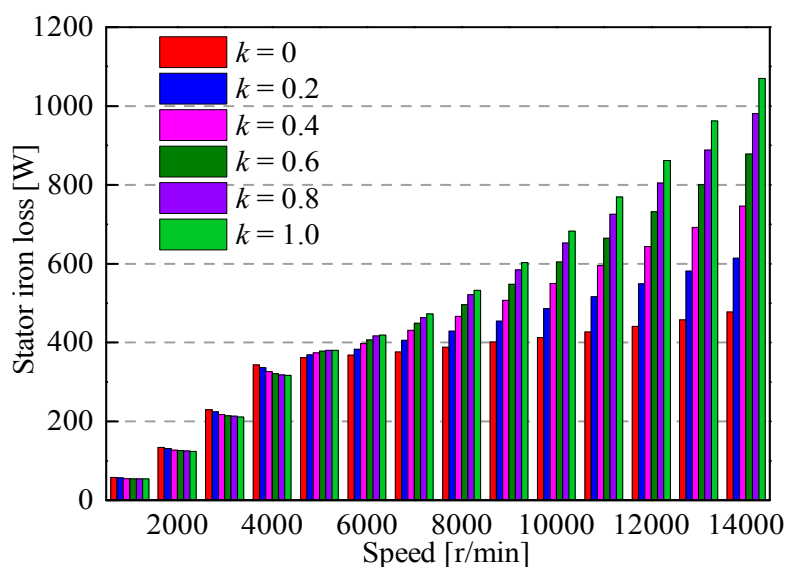

(b)

Fig 12. Iron loss. (a) Rotor iron loss. (b) Stator iron loss.

The efficiency map of PMASynRM with different magnet ratio is shown in Fig. 13, where MTPA control strategy is adopted. It should be noted that the eddy current losses in the armature windings and PM eddy loss are not considered when computing the efficiency of PMASynRM. The mechanical frication losses is set to $50 \mathrm{~W}$, which references to mechanical frication losses at $3000 \mathrm{r} / \mathrm{min}$. The copper loss is calculated by 2-D FEA at $20^{\circ} \mathrm{C}$, and the effect of temperature variation on copper loss is neglected. The maximum efficiency is about $96.0 \%, 96.2 \%, 96.5 \%, 96.7 \%, 96.8 \%$ and $97.0 \%$ when magnet ratio $k$ is $0,0.2,0.4,0.6,0.8$ and 1 , respectively, as shown in Fig. 13. The efficiency of PMASynRM with different magnet ratio is over $90 \%$ across a wide operating range. Especially, the area of efficiency that more than $90 \%$ is the largest when $k$ is 1 . Meanwhile, the area of efficiency that more than $96 \%$ increased with magnet ratio, and the preferable efficiency distribution is obtained when $\mathrm{k}$ is 0.6 . Nevertheless, the area of efficiency that more than $96 \%$ will be reduced when $k$ is 0.8 and 1. It is decided by the flux saturation and increasing iron loss in rotor and stator. In addition, it can be observed that the excellent efficiency distribution can be obtained in PMASynRM with 
different magnet ratio. The above characteristics demonstrated that the high efficiency can be achieved in PMASynRM by using rare-earth PMs and ferrite magnets with different magnet ratio.

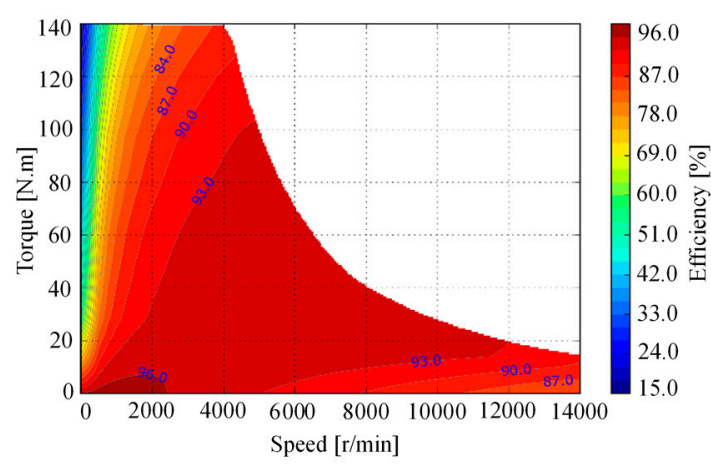

(a)

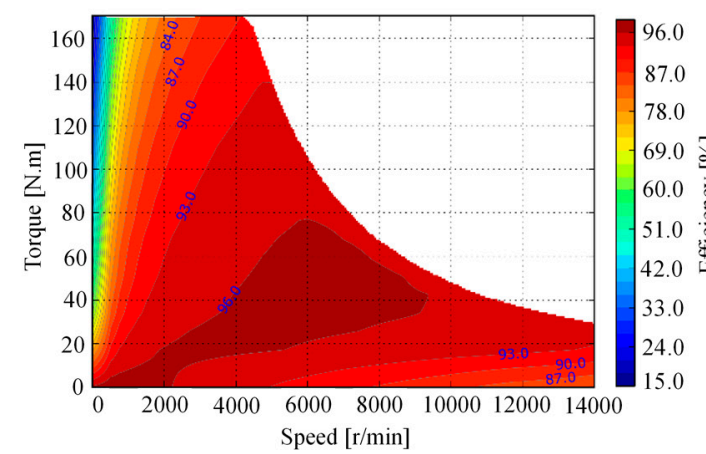

(c)

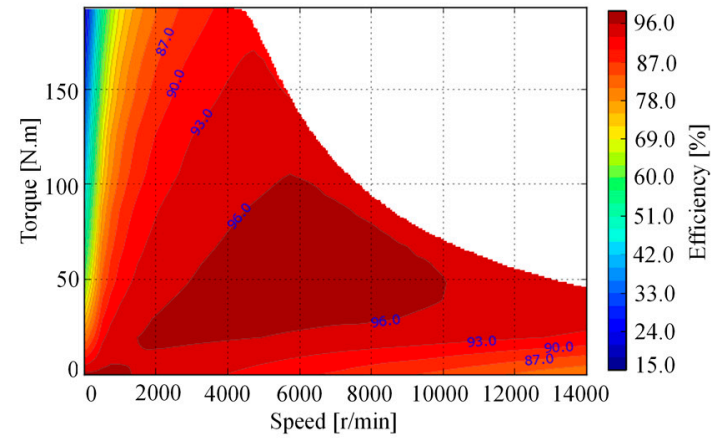

(e)

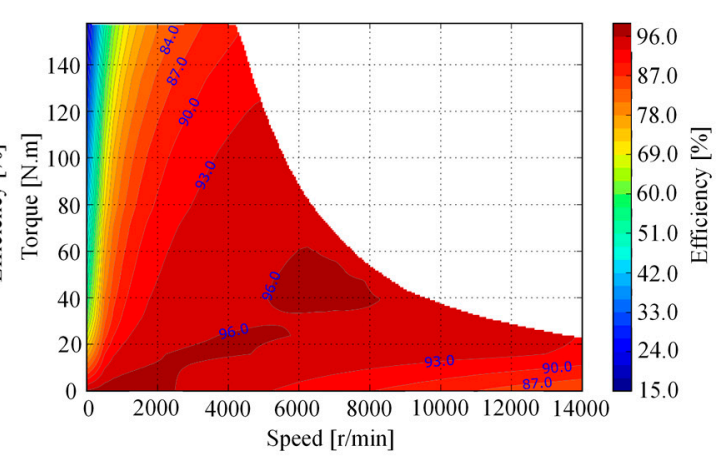

(b)

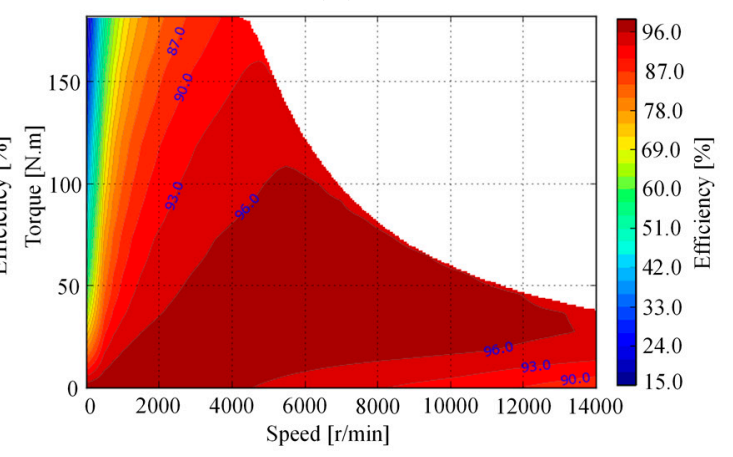

(d)

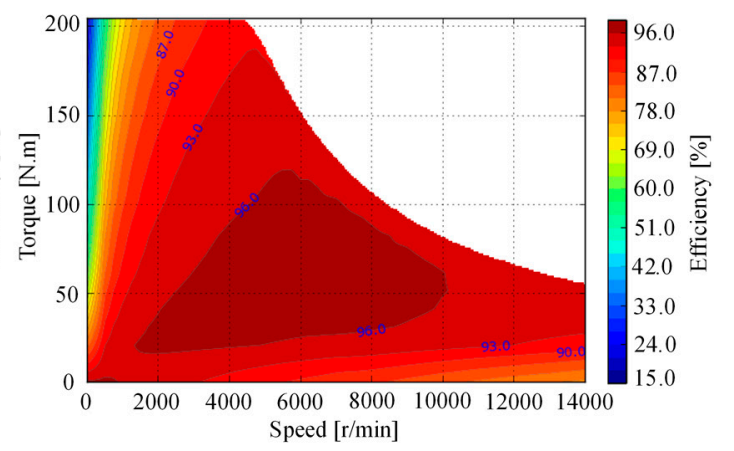

(f)

Fig 13. Efficiency maps. (a) $k=0$. (b) $k=0.2$. (c) $k=0.4$. (d) $k=0.6$. (e) $k=0.8$. (f) $k=1$.

\section{Irreversible Demagnetization}

The capability of withstand demagnetization is crucial to PM machines for the safe operation. In order to estimate the worst condition, the irreversible demagnetization is calculated in PMASynRM. Although the rare-earth PMs will be demagnetized at high temperature, the temperature of machine may be lower than the highest working temperature of rare-earth PMs by using some cooling methods. Hence, the demagnetization of rare-earth PMs can be neglected in this paper. Owing to the performance of ferrite magnets are effected in cold weather, which results in a deterioration of machine performance. Consequently, the demagnetization of ferrite magnets of Y30BH should be investigated, and the lowest temperature is set to $-40^{\circ} \mathrm{C}$.

The demagnetization curve of ferrite magnet $(\mathrm{Y} 30 \mathrm{BH})$ used in the proposed PMASynRM is shown in Fig. 14. The irreversible demagnetization will be occurred when the flux density of Y30BH is lower than the critical flux density at the knee of demagnetization curve. The knee of irreversible demagnetization is about $0.15 \mathrm{~T}$ (with margin) at $-40{ }^{\circ} \mathrm{C}$, as shown in Fig. 14. The rate of irreversible 
demagnetization is calculated by the magnet number of demagnetization against the total magnet number, and this is called "demagnetization rate" (DR). In order to simulate the severest condition, the phase current with opposite direction of magnetomotive force (MMF) produced by ferrite magnets is applied. The phase current is about $500 \mathrm{~A}$, which is 2.5 times of rated current.

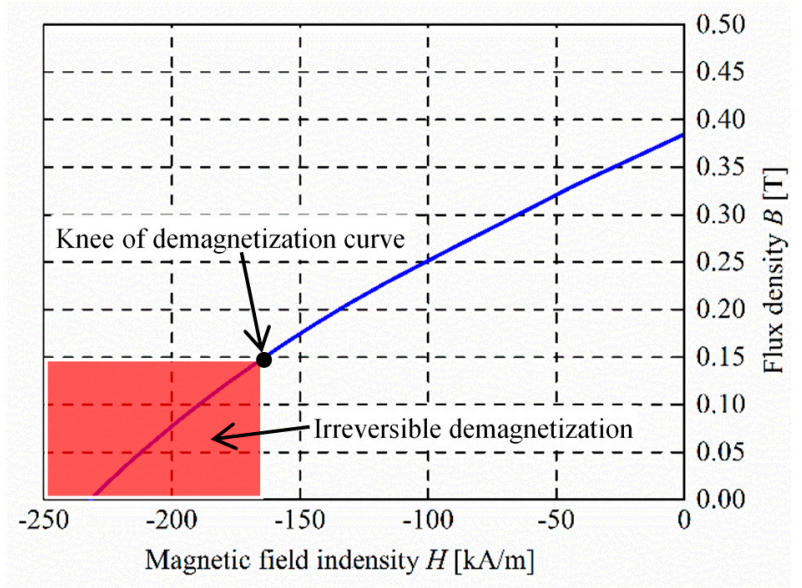

Fig 14. Demagnetization curve of ferrite magnet (Y30BH).

Fig. 15 shows the contour plots of flux density at $500 \mathrm{~A}$. It shows that the ferrite magnets of the fourth-layer is partial irreversibly demagnetized, as shown in Fig. 15(a). Due to the MMF from the stator winding, the flux flows primarily through the center ribs and iron bridges. However, the flux also flows through the flux barriers because the thickness of flux barriers is smaller than that of ferrite magnets. So the flux density is too low in side part of ferrite magnets, and the irreversible demagnetization is occurred. However, the irreversible demagnetization rate is only about $5.3 \%$, and the irreversible demagnetization is not occurred when $k$ is $0.2,0.4,0.6$ and 0.8 due to the increase of MMF by adopting rare-earth PMs, as shown in Fig .15(b), (c), (d) and (e), respectively. The magnet flux in ferrite magnets become large with the increase of magnet ratio due to the more rare-earth PMs are applied, as shown in Fig. 15(b), (c), (d) and (e).

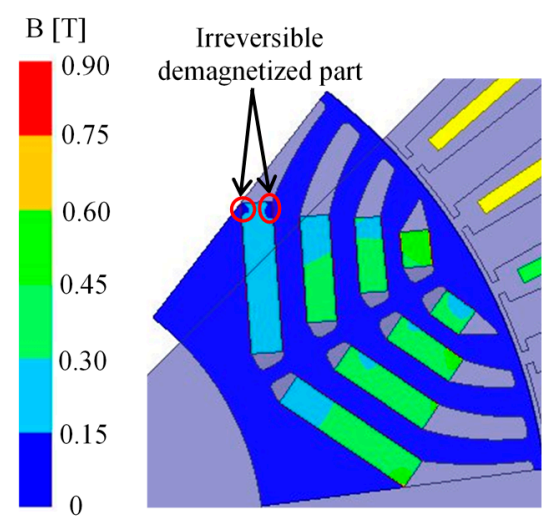

(a)

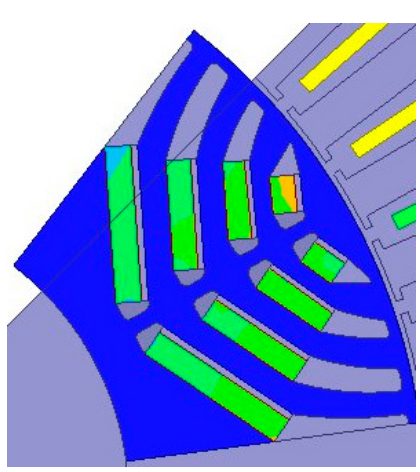

(b)

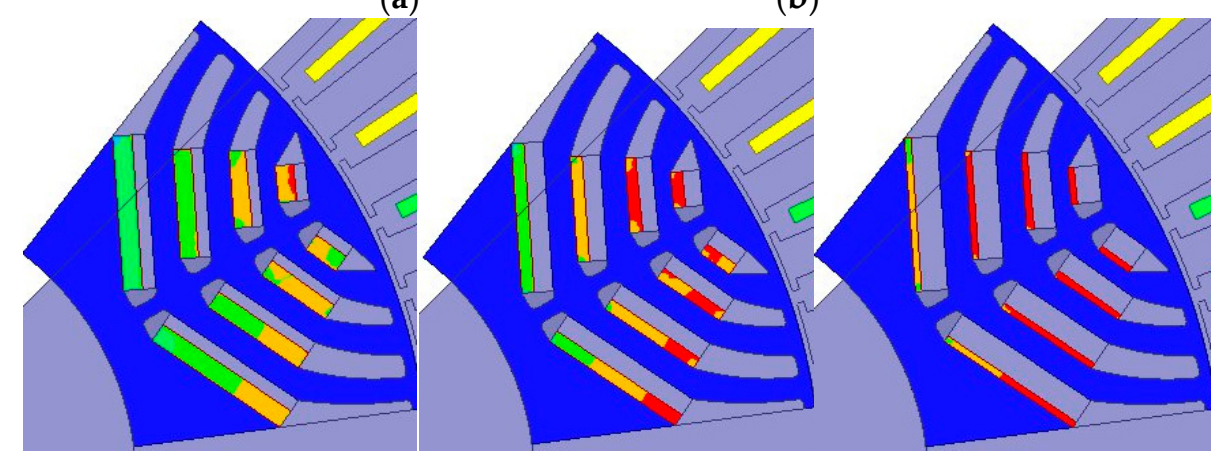


(c)

(d) (e)

Fig 15. Contour plots of flux density at $500 \mathrm{~A}$. (a) $k=0$. (b) $k=0.2$. (c) $k=0.4$. (d) $k=0.6$. (e) $k=0.8$.

\section{Comparison of PMASynRM with Different Magnet Ratio}

Some parameters including torque density, power density, PM material costs and the maximum efficiency are compared for PMASynRM with different magnet ratio, as shown in Table 2. It should be worth mentioning that all PMASynRMs have the same structure and excitations, and the only difference is magnet ratio. The proposed PMASynRM with rare-earth PMs has the highest torque density, power density and total cost, which is 1.46, 1.65, and 301 times of ferrite magnets, respectively. It indicated that potentially offer some desirable cost-performance trade-off. Therefore, if there is no limit to the machine volume, the total cost of PMASynRM can be reduced for obtaining the same output torque by using low-cost ferrite magnets. In addition, the high torque density can be obtained in the proposed PMASynRM when the multi-layer structure of rotor is adopted by using hybrid magnets. The proposed PMASynRM can be applied in aerospace, vehicle traction, industrial application, and energy power generation.

Table 2. Some parameters with different magnet ratio.

\begin{tabular}{|c|c|c|c|c|c|c|}
\hline Parameter (Unit) & $k=0$ & $k=0.2$ & $k=0.4$ & $k=0.6$ & $k=0.8$ & $k=1$ \\
\hline Max. torque [N.m] & 140.1 & 157.7 & 170.4 & 181.6 & 192.6 & 204.5 \\
\hline Max. power [kW] & 59.9 & 69.9 & 77.9 & 84.7 & 91.4 & 98.7 \\
\hline Max. efficiency [\%] & 96.0 & 96.2 & 96.5 & 96.7 & 96.8 & 97.0 \\
\hline Volume [L] & \multicolumn{6}{|c|}{5.9} \\
\hline Power density [kW/L] & 10.15 & 11.85 & 13.20 & 14.36 & 15.49 & 16.73 \\
\hline $\begin{array}{l}\text { Torque density } \\
{[\text { N.m/L] }}\end{array}$ & 23.75 & 26.73 & 28.88 & 30.78 & 32.64 & 34.66 \\
\hline N36_Z20 volume $\left[\mathrm{cm}^{3}\right]$ & 0 & 48.8 & 97.8 & 146.8 & 196.7 & 244.6 \\
\hline N36_Z20 price $[¥ / \mathrm{kg}]^{*}$ & \multicolumn{6}{|c|}{4342.1} \\
\hline N36_Z20 cost [¥] & 0 & 1611 & 3227 & 4844 & 6491 & 8072 \\
\hline Y30BH volume $\left[\mathrm{cm}^{3}\right]$ & 244.6 & 196.7 & 146.8 & 97.8 & 48.8 & 0 \\
\hline Y30BH price $[¥ / \mathrm{kg}]^{*}$ & \multicolumn{6}{|c|}{14.4} \\
\hline Y30BH cost [¥] & 26.8 & 21.5 & 16.1 & 10.7 & 5.3 & 0 \\
\hline Total cost $[¥]$ & 26.8 & 1633 & 3243 & 4854 & 6496 & 8072 \\
\hline
\end{tabular}

\section{Conclusion}

A novel rotor structure of PMASynRM with different magnet ratio is presented in this paper. Some electromagnetic characteristics including output torque, cogging torque, output power, power factor, torque ripple, loss and efficiency are obtained by FEA. Moreover, the irreversible demagnetization are investigated in the worst condition at critical temperature of $-40^{\circ} \mathrm{C}$. The analysis results show that high power density, high torque density, high power factor and high efficiency of PMASynRM can be achieved with a suitable magnet ratio. In particular, if there is no limit for machine volume, high performance could be obtained by using low-cost ferrite magnets for same output torque. On the contrary, the more rare-earth PMs should be applied when power factor and torque density are need to be improved. In addition, it provides a way for desirable cost-performance trade-off.

As for future work, the hybrid magnet with parallel-excited will be investigated in PMASynRM, and compare with serial-excited of hybrid magnet, in order to improve the torque density, power factor and efficiency.

\section{Acknowledgment}


This work is supported by National Natural Science Foundation of P.R.China (No.51267006), Plan Project of Jiangxi Province of P.R.China (GJJ12332, 20122BAB206031, 20151BBE50109), Program of Qingjiang Excellent Young Talents, JXUST.

\section{References}

1. Nerg, J.; Rilla, M.; Ruuskanen, V.; Pyrhonen, J.; Ruotsalainen, S. Direct-Driven Interior Magnet PermanentMagnet Synchronous Motors for a Full Electric Sports Car, IEEE Trans. Ind. Elec. 2014， 61, 4286-4294.

2. Galioto, S.J.; Reddy, P.B.; EL-Refaie, A.M.; and Alexander, J.P. Effect of Magnet Types on Performance of High-Speed Spoke Interior-Permanent-Magnet Machines Designed for Traction Applications, IEEE Trans. Ind. Appl. 2015, 51, 2148-2150.

3. Abdel-Khalik, A.S.; Ahmed, S.; Massoud, A.M. Effect of Multilayer Windings with Different Stator Winding Connections on Interior PM Machine for EV Applications, IEEE Trans. Magn. 2016, 52, 8100807.

4. Ding, W.; Hu, Y.; Wu, L. Analysis and Development of Novel Three-Phase Hybrid Magnetic Paths Switched Reluctance Motors Using Modular and Segmental Structures for EV Applications, IEEE Trans. Mech. 2015, 20, 3427-2451.

5. Kiyota, K.; Kakishima, T.; Sugimoto, H.; Chiba, A. Comparison of the Test Result and 3D-FEM Anlysis at the Knee Point of a 60 kW SRM for a HEV, IEEE Trans Magn. 2013, 49, 2291-2294.

6. Nezamabadi, M.M.; Afjei, E.; Torkaman, H. Design, Dynamic Electromagnetic Analysis, FEM, and Fabrication a New Switched Reluctance Motor with Hybrid Motion, IEEE Trans Magn. 2016, 52, 8201708.

7. Takeno, M.; Chiba, A.; Hoshi, N.; Ogasawara, S.; Takemoto, M.; Rahman, M. A. Test Results and Torque Improvement of the 50-kW Switched Reluctance Motor Designed for Hybrid Electric Vehicles, IEEE Trans. Ind. Appl. 2012, 48, 2874-2883.

8. Chiba, A.; Takano,Y.; Takeno, M.; Imakama, T.; Hoshi, N.; Takemoto, M.; Ogasawara, S.; Torque Density and Efficiency Improvements of a Switched Reluctance Motor Without Rare-Earth Material for Hybrid Vehicles, IEEE Trans. Ind. Appl. 2011, 47, 1240-1246.

9. Moghaddam, R.R.; Gyllensten, F. Novel High-Performance SynRM Design Method: A Easy Approach for A Complicated Rotor Topology, IEEE Trans. Ind. Elec. 2014, 1, 5058-5065.

10. Cai, H.; Guan, B.; Xu, L.; Choi, W. Optimal design of synchronous reluctance machine, COMPEL, 2014, 33, 1569-1586.

11. Zhang, X.; Beng Foo, G.H.; Vilathgamuwa, D.M.; Maskell, D.L. An Improved Robust Field-Weakening Algorithm for Direct-Torque-Controlled Synchronous-Reluctance-Motor Drives, IEEE Trans. Ind. Elec. 2015, $62,3255-3264$.

12. Daryabeigi, E.; Zarchi, H. A.; Arab Markadeh, G. R.; Soitani, J.; Blaabjerg, F. Online MTPA Control Approach for Synchronous Reluctance Motor Drive Based on Emotional Controller, IEEE Trans. Power Electronics. 2015, 30, 2157-2166.

13. Kiyota, K.; Kakishima, T.; Chiba, A.; Rahaman, M.A.; Cylindrical Rotor Design for Acoustic Noise and Windage Loss Reduction in Switched Reluctance Motor for HEV Applications, IEEE Trans. Ind. Appl. 2016, 52, 154-162.

14. Bayless, J.; Kurihara, N.; Sugimoto, H.; Chiba, A. Acoustic Noise Reduction of Switched Reluctance Motor with Reduced RMS Current and Enhanced Efficiency, IEEE Trans. Energy. Con. 2015, pp, 1-10.

15. Rasmussen, P.O.; Andreasen, J.H.; Pijanowski, J.M.; Structural Stator Spaces-A Solution for Noise Reduction of Switched Reluctance Motors, IEEE Trans. Ind. Appl. 2004, 40, 574-561.

16. Sato, S.; Sato, T.; Igarshi, H. Topology Optimization of Synchronous Reluctance Motor Using Normalized Gaussian Network, IEEE Trans. Magn. 2015, 51, 8200904. 
17. Moghaddam, R.R.; Gyllensten, F.; Novel High-Performance SynRM Design Method: An Easy Approach for A Complicated Rotor Topology, IEEE Trans. Ind. Elec. 2014, 61, 5058-5065.

18. Pellegrino, G.; Cupertino, F.; Gerada, C. Automatic Design of Synchronous Reluctance Motors Focusing on Barrier Shape Optimization, IEEE Trans. Ind. Appl. 2015, 51, 1465-1474.

19. Duck, P.; Jurgens, J.; Ponick, B. Calculation of Synchronous Reluctance Machines Used as Traction Drives, in Proc. VPPC, Oct. 19-22, 2015, pp. 1-5.

20. Morimoto, S.; Ooi, S.; Inoue, Y.; Sanada, M. Experimental Evaluation of a Rare-Earth-Free PMASynRM With Ferrite Magnets for Automotive Applications, IEEE Trans. Ind. Elec. 2014, 61, 5749-5756.

21. Sanada, M.; Inoue, Y.; Morimoto, S. Structure and Characteristics of High-Performance PMASynRM with Ferrite Magnets, Electrical Engineering in Japan. 2014, 187, 42-50.

22. Ooi, S.; Morimoto, S.; Sanada, M.; Inoue, Y. Performance Evaluation of a High-Power-Density PMASynRM with Ferrite Magnets, IEEE Trans. Ind. Appl. 2013, 49, 1308-1314.

23. Cai, H.; Guan, B.; Xu, L.; Low-Cost Ferrite PM-Assisted Synchronous Reluctance Machines for Electric Vehicles, IEEE Trans. Ind. Elec. 2014, 61, 5741-5748.

24. Kim,W.H.; Kim, K.S.; Kim, S.J.; Kang, D.W.; Go, S.C.; Chun, Y.D.; Lee, J. Optimal PM Design of PMASynRM for Wide Constant-Power Operation and Torque Ripple Reduction, IEEE Trans. Magn. 2009, 45, 4660-4663.

25. Boldea, I.; Tutelea, L.; Pitic, C.I. PM-Assisted Reluctance Synchronous Motor/Generator (PM-RSM) for Mild Hybrid Vehicles: Electromagnetic Design, IEEE Trans. Ind. Appl. 2004, 40, 492-498.

26. Kondo, K.; Kusase, S.; Maekawa, T.; Hanada, K. A New PM-Assisted Synchronous Reluctance Motor With Three-Dimensional Trench Air Gap, IEEE Trans. Ind. Appl. 2014, 50, 2485-2492.

27. Bianchi, N.; Fornasiero, E.; Soong, W.; Selection of PM Flux Linkage for Maximum Low-Speed Torque Rating in a PM-Assisted Synchronous Reluctance Machine, IEEE Trans. Ind. Appl. 2015, 51, 3600-3608.

28. Chen, X.; Wang, J.; Lazari, P.; Chen, L. Permanent Magnet Assisted Synchronous Reluctance Machine with Fractional-Slot Winding Configurations, in Proc. IEMDC, May. 12-15, 2013, pp. 374-381.

29. Yamazaki, K.; Tamiya, S.; Utsuno, K.; Shima, K.; Fukami, T.; Sato, M. Rotor Shape Optimization for Output Maximization of Permanent-Magnet-Assisted Synchronous Machines, IEEE Trans. Ind. Appl. 2015, 51, 30773085.

30. Kim, S.I.; Park, S.; Park, T.; Cho, J.; Kim, W.; Lim, S. Investigation and Experimental Verification of a Novel Spole-Type Ferrite-Magnet Motor for Electric-Vehicles Traction Drive Applications, IEEE Trans. Ind. Elec. 2014, 61, 5763-5770.

31. Barcaro, M.; Bianchi, N.; Magnussen, F. Permanent-Magnet Optimization in Permane-Magnet-Assisted Synchronous Reluctance Motor for a Wide Constant-Power Speed Range, IEEE Trans. Ind. Elec. 2012, 59, 2495-2502.

32. Lohninge, R.; Grabner, H.; Weidenhozer, G.; Silber, S.; Amrhein, W.; Modeling, Simulation, and Design a Permanent -Magnet-Assisted Synchronous Reluctance Machine, IEEE Trans. Ind. Appl. 2015, 50, 196-203.

33. Huang, H.; Hu, Y.S.; Xiao, Y.; Lyu, H. Research of Parameters and Anti-demagnetization of Rare-Earth-Less Permanent Magnet-Assisted Synchronous Reluctance Motor, IEEE Trans Magn. 2015, 51, 8112504.

34. Vagati, A.; Boazzo, B.; Guglielmi, P.; Pellegrino, G. Design of Ferrite-Assisted Synchronous Reluctance Machines Robust Toward Demagnetization, IEEE Trans. Ind. Appl. 2014, 50, 1768-1779.

35. Sanada, M.; Inoue, Y.; Morimoto, S. Rotor Structure for Reducing Demagnetization of Magnet in a PMASynRM with Ferrite Permanent Magnet and its Characteristics, in Proc. Energy Convers. Congr. Expo. (ECCE), 2011, pp. 4189-4194. 
36. Liu, X.; Li, Y.; Liu, Z.; Ling, T.; Luo, Z. Analysis and Design of a High Power Density Permanent MagnetAssisted Synchronous Machine with Low-cost Ferrite Magnets for EVs/HEVs, COMPEL, 2016, 35, 1949-1964.

37. Sanada, M.; Hiramoto, K.; Morimoto, S.; Takeda, Y. Torque Ripple Improvement for Synchronous Reluctance Motor Using an Asymmetric Flux Barrier Arrangement, IEEE Trans. Ind. Appl. 2004, 40, 10761082.

38. Bianchi, N.; Bolognani, S.; Bon, D.; Pre, M.D. Rotor Flux-Barrier Design for Torque Ripple Reduction in Synchronous Reluctance and PM-Assisted Synchronous Reluctance Motors, IEEE Trans. Ind. Appl. 2009, 45, 921-927.

39. Wang, K.; Zhu, Z.Q.; Ombach, G.; Koch, M.; Zhang, S.; Xu, J. Torque ripple reduction of synchronous reluctance machines: using asymmetric flux-barrier, COMPEL, 2015, 34, 18-31.

(C) 2017 by the authors; licensee Preprints, Basel, Switzerland. This article is an open access article distributed under the terms and conditions of the Creative Commons by Attribution (CC-BY) license (http://creativecommons.org/licenses/by/4.0/). 